\title{
Bioengineering and phytomedicines among FY00 congressional priorities
}

Despite being subject to a delay of almost two months while the president, the House of Representatives and the Senate postured over the details and direction of the FYO0 Education Appropriations Bill, it was worth the wait-for biomedical research, at least.

Following on from last year's bumper budget, the US National Institutes of Health (NIH) has once again benefited from Congress' desire to invest heavily in biomedical research and prioritize it above other areas of scien-

tific $R \& D$ as a means of improving the nation's quality of life. The NIH received an FYOO increase of $\$ 2.2$ billion (14.3\% over FY99), bringing its total funds to $\$ 17.8$ billion.

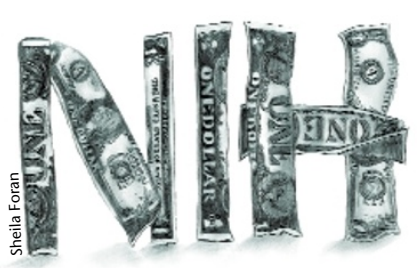
feedback from NIH on

In absolute terms, this year's biggest winners are the two largest institutes: the National Cancer Institute (NCI), which topped the \$3 billion mark for the first time with $\$ 3.3$ billion, and the National Heart, Lung and Blood Institute, which now boasts a budget of $\$ 2.04$ billion. But the biggest relative increase has gone to the National Center for Complementary and Alternative Medicine, which receives \$68 million-a considerable leap from its inaugural budget of $\$ 20$ million two years ago, reflecting its popularity with members of Congress (Nature Med. 4, 1348; 1998).

In addition to the funds meted out by the House Appropriations Subcommittee on Labor, Health \& Human Services and Education, for FY00 there is a new Senate provision of $\$ 20$ million to promote joint ventures between the NIH and the biotechnology, pharmaceutical and medical device industries. The money is to be distributed-most likely by the National Institute of Allergy and Autoimmune Diseases-as a matching one-to-one fund, such that if all funds are matched, NIH-industrial collaboration will be $\$ 40$ million richer.

The Senate committee has indicated that it wishes this money to be spent on "accelerating the development of new antimicrobials, antivirals and vaccines" against antibiotic-resistant strains of viruses and bacteria. It calls for bioprospecting research programs centered on the discovery and development of potential pharmaceutical agents from plants, for which the NIH is urged to develop collaborations with organizations worldwide.

The House Appropriations Subcommittee does not officially tell the NIH how to spend its money, but it does make several detailed recommendations as to which areas of research it believes will benefit the American public most. Thus, although not binding, the report language of the Congressional Record released within recent weeks make certain suggestions for NIH expenditure and requests these issues.

For FY00, the subcommittee has been highly critical of the NIH's approach to biomedical engineering and

efforts in, "basic and clinical research into the cause, diagnosis, early detection, prevention, control and treatment of autism," including research in the fields of "developmental neurobiology, genetics, and psychopharmacology." The NIH was encouraged to enhance research into possible links between gastrointestinal conditions and autism.

The NIH was also requested to present a report to Congress by 1 March 2000 outlining an agenda for research focused on Parkinson disease over the next five years, as a way of fulfilling the goals of the Morris K. Udall Parkinson's Research Act of 1997. This Act includes the establishment of ten Morris K. Udall Research Centers-three of which have been created so far.

The genetic plight of Ashkenazi Jewish women was also singled out. This population has an increased frequency of mutation of the BRCA 1 gene, giving rise to an abnormally high incidence of breast and ovarian cancer. Congress asked that the NCI and the National Human genome Research Institute-which received a 27\% increase, to $\$ 336$ million-coordinate US-Israeli research activities, "including the establishment of a computerized data and specimen sharing system, subject recruitment programs."

One small blot on the funding landscape is that $\$ 3$ billion of the $\$ 17.8$ billion budget has been cordoned off, not to be spent until the start of the next fiscal year on 1 October 2000. This money, called "delayed obligation" or "forward funding," is an accounting trick designed to delay expenditure of surplus money to comply with the Balanced Budget Act of 1997. Highlights of the FY00 appropriations are available at http://www4.od.nih.gov/ofm/budget/ FY00odhighlights.htm

Karen Birmingham, London

In disease terms, autism and Parkinson disease received special mention. Congress noted that there has never been a national prevalence study of autism in the US, a void that leaves room for the suggestion that, based on data from other countries, the prevalence of the condition may be substantially higher than previously estimated. Around 400,000 Americans are thought to suffer from some form of autism.

Thus, through the NIH's Autism Coordinating Committee, Congress urged more resources for, and increased
Nature Medicine feedback...

Questions, comments, complaints? We welcome feedback on the news presented here in the print issue of Nature Medicine and in the "Breaking News" feature on our website (http://medicine. nature.com) Please send your comments on the news (or any other aspect of Nature Medicine) to the Associate Editor, News at k.birmingham@nature.com. 